\title{
CD36 selection of 3D7 Plasmodium falciparum associated with severe childhood malaria results in reduced VAR4 expression Pamela A Magistrado*1, Trine Staalsoe ${ }^{2}$, Thor G Theander ${ }^{1}$, Lars Hviid ${ }^{2}$ and Anja TR Jensen ${ }^{1}$
}

Address: ${ }^{1}$ Centre for Medical Parasitology at the Institute of International Health, Immunology and Microbiology, University of Copenhagen, Copenhagen, Denmark and ${ }^{2}$ Centre for Medical Parasitology at the Institute of International Health, Immunology and Microbiology, Department of Clinical Microbiology, Copenhagen University Hospital (Rigshospitalet), Copenhagen, Denmark

Email: Pamela A Magistrado* - pam@immi.ku.dk; Trine Staalsoe - staalsoe@cmp.dk; Thor G Theander - theander@cmp.dk; Lars Hviid - lhcmp@rh.dk; Anja TR Jensen - atrj@cmp.dk

* Corresponding author

Published: 9 October 2008

Malaria Journal 2008, 7:204

doi:| 0. I |86//475-2875-7-204
Received: I 4 March 2008

Accepted: 9 October 2008

This article is available from: http://www.malariajournal.com/content/7/1/204

(c) 2008 Magistrado et al; licensee BioMed Central Ltd.

This is an Open Access article distributed under the terms of the Creative Commons Attribution License (http://creativecommons.org/licenses/by/2.0), which permits unrestricted use, distribution, and reproduction in any medium, provided the original work is properly cited.

\begin{abstract}
Background: A subset of the Plasmodium falciparum erythrocyte membrane protein I (PfEMPI $\mathrm{SM}$ ) is involved in the cytoadherence of $P$. falciparum-infected red blood cells (iRBC) contributing to the pathogenesis of severe disease among young children in malaria endemic areas. The PfEMPI ${ }_{S M}$ are encoded by group $A$ var genes that are composed of a more constrained range of amino acid sequences than groups $B$ and $C$ var genes encoding PfEMPI ${ }_{U M}$ associated with uncomplicated malaria. Also, unlike var genes from groups $B$ and $C$, those from group $A$ do not have sequences consistent with CD36 binding - a major cytoadhesion phenotype of $P$. falciparum isolates.

Methods: A 3D7 PfEMPI ${ }_{S M}$ sub-line (3D7 ${ }_{S M}$ ) expressing VAR4 (PFDI235w/MAL8PI.207) was selected for binding to CD36. The protein expression of this parasite line was monitored by surface staining of $i R B C$ using VAR4-specific antibodies. The serological phenotype of the $3 D 7_{S M}$ parasites was determined by flow cytometry using malaria semi-immune and immune plasma and transcription of the 59 var genes in 3D7 were analysed by real-time quantitative reverse transcriptase-polymerase chain reaction (RT-PCR) using var-specific primers.
\end{abstract}

Results: A selection-induced increased adhesion of $3 D 7_{S M} i R B C$ to $C D 36$ resulted in a reduced var4 transcription and VAR4 surface expression.

Conclusion: VAR4 is not involved in CD36 adhesion. The current findings are consistent with the notion that CD36 adhesion is not associated with particular virulent parasite phenotypes, such as those believed to be exhibited by VAR4 expressing parasites.

\section{Background}

Variant surface antigens (VSA) on the Plasmodium falciparum-infected red blood cells (iRBC) are involved in both cytoadherence contributing to disease pathology [18 ] and immune evasion which probably contributes to the severity and persistence of malaria infections [9-11]. Anti-VSA antibodies have been shown to contribute to protective immunity [12-16] and data from several studies indicate that some important targets for immunity seem to have restricted heterogeneity. 
The Plasmodium falciparum Erythrocyte Membrane Protein-1 (PfEMP1) is the most studied VSA. PfEMP1 molecules are encoded by the var gene family comprising 5060 highly diverse genes per haploid genome [17-22]. Any single parasite nuclei transcribes only one variant at a time, a phenomenon referred to as allelic exclusion or mutually exclusive expression [20,23-26]. Cultures of unselected 3D7 parasites predominantly express PfEMP1 mRNA species resembling those of parasites causing uncomplicated malaria (PfEMP $\left.1_{\mathrm{UM}}\right)$. The dominant serological phenotype (recognition by semi-immune and immune human plasma) changes to PfEMP $1_{S M}$ following selection of 3D7 using DynaBeads coated with IgG from semi-immune children [27]. This $3 \mathrm{D} 7_{\mathrm{SM}}$ shows transcriptional upregulation and protein surface expression of one particular group A var gene, var4 (PFD1235w/ MAL8P1.207)[28]. More recently, group A var genes, together with certain other B/A type were found to be transcribed in isolates from children with cerebral malaria, but not from isolates from equally highly parasitaemic patients without severe malaria syndromes [29].

Group A var genes are one of three major groups (A, B and C) of 3D7 var gene sequences categorized according to chromosomal location, gene orientation, domain structure of the encoded proteins and similarities in coding and non-coding regions. Group A contains seven genes encoding large PfEMP1s of about $400 \mathrm{kDa}$, with complex domain arrangements and three genes encoding PfEMP1s of about $150 \mathrm{kDa}[30,31]$. Unlike most other var genes from group B and C, the Group A var genes do not encode sequences thought to be consistent with binding to CD36, a major endothelial receptor for iRBC sequestration [31]. It should be noted however that the correlation between severity, binding phenotype and var gene expression is not clear-cut $[4,32]$.

In this study, changes in the transcription of all var genes and surface expression levels of VAR4 as a result of drifting and changes following selection for binding of $3 \mathrm{D} 7_{S M}$ to CD36 was investigated.

\section{Methods \\ Parasites}

All parasites used in this study were derived from the $P$. falciparum isolate, 3D7 and were cultured in O Rh+ RBCs as described previously [33]. Three 3D7 sub-lines were used, namely: $3 \mathrm{D} 7_{\mathrm{SM}-\mathrm{CD} 36}, 3 \mathrm{D} 7_{\mathrm{SM} \text {-drift }}$ and $3 \mathrm{D} 7_{\mathrm{UM}}$.

$3 \mathrm{D} 7_{\mathrm{SM}-\mathrm{CD} 36}$ was obtained by bio-panning $3 \mathrm{D} 7_{\mathrm{SM}}$ on Chinese hamster ovary $(\mathrm{CHO})$ cells expressing $\mathrm{CD} 36.3 \mathrm{D}_{\mathrm{SM}}$ has previously been selected from 3D7 using a pool of plasma from semi-immune Ghanaian children $[27,28]$. To select for a CD36-binding $3 \mathrm{D} 7_{\mathrm{SM}}$ population, the method described in [27] was followed. Gelatine enriched late-stage $3 \mathrm{D} 7_{\mathrm{SM}}$ was panned on a monolayer of wild-type $\mathrm{CHO}$ cells. Unbound iRBC and uninfected RBC (uRBC) were then panned on $\mathrm{CHO}$ cells transfected with human CD36. The monolayer was washed repeatedly to remove unbound iRBC and uRBC. To allow bound $3 \mathrm{D}_{\text {SM }}$ parasites to reinvade and grow, culture medium and $\mathrm{URBC}$ were added to the monolayer of CD36-transfected $\mathrm{CHO}$ cells and incubated overnight.

$37_{\text {SM }}$ was allowed to drift without routine selection using the Ghanaian plasma pool to obtain the subline $3 \mathrm{D} 7_{\text {SM-drift }}$ For consistency, $3 \mathrm{D} 7_{\text {SM-drift }}$ and unselected 3D7 were late-stage enriched by gelatine flotation [34] every time 3 D7 ${ }_{\text {SM-CD } 36}$ was selected for CD36 binding. The gelatine-enriched unselected $3 \mathrm{D} 7$ was termed $3 \mathrm{D} 7_{\mathrm{UM}}$ and was serologically similar to parasites causing uncomplicated malaria [27].

The genotypic identity of the 3D7 isolate and its derived sub-lines were confirmed by PCR at the polymorphic $m s p 1, m s p 2$, and glurp loci [35].

\section{Immuno-staining of live cells and flow cytometry}

Immuno-staining and flow cytometry were carried out as described [28,33] with minor modifications. To monitor VAR4 expression on the surface of live cells, late stageiRBC were enriched by magnet-activated cell sorting (MACS, Miltenyl BioTec, Bergisch Gladbach, Germany)[36,37]. MACS purified and ethidium bromidelabeled iRBC $\left(2.5 \times 10^{5}\right)$ was incubated for $1 \mathrm{hr}$ in $20 \mu \mathrm{L}$ mouse sera or $40 \mu \mathrm{L}$ rabbit sera raised against the CIDR $1 \alpha$ or DBL5 $\delta$ domains of VAR4[28] depleted for anti-human RBC antibodies prior to use. To detect surface bound antibodies, the iRBC were sequentially exposed to $100 \mu \mathrm{L}$ of 1:25 goat anti-mouse or anti-rabbit Ig (DAKO), biotinylated anti-goat Ig (DAKO) and 1:1,000 fluorescein isothiocyanate (FITC)-conjugated streptavidin (BD Pharmingen) for 30 minutes each. For serological phenotyping, 20 human plasma samples from Magoda village in Tanzania with high malaria transmission were used to determine the recognition profile of the various parasite lines. Out of the 20 Magoda plasma samples, 10 came from children aged 3-5 years and 10 came from adolescents and adults aged $12-63$ years. Staining of the iRBC by human IgG was done by incubating $2.5 \times 10^{5}$ MACS purified ethidium bromide-labeled iRBC in $5 \mu \mathrm{L}$ human plasma for 30 minutes and then sequentially exposed to $100 \mu \mathrm{L}$ of $1: 50$ biotinylated rabbit anti-human IgG (DAKO) and 1:2000 FITC-conjugated streptavidin (DAKO) for 30 minutes each. All immuno-stained samples were analysed in a Coulter EPICS XL-MCL flow cytometer (Coulter Electronics, Luton, UK) or in a FACScan (Becton Dickinson). Data were analysed in WinMDI software http://facs.scripps.edu/software.html and WinList version 5.0 (Verity Software House, Inc., Maine, USA). 
Student's t-test was used to determine whether the samples compared were significantly different $(\mathrm{P}=\leq 0.05)$.

\section{RNA extraction, CDNA synthesis and Quantitative Real- Time PCR}

RNA extraction, cDNA synthesis and quantitative realtime PCR were done as previously described $[28,38]$. Trophozoite/schizont-iRBC (36-48 h after invasion) were isolated from mixed stage in vitro cultures by exposure to a strong magnetic field as described in the previous section. To obtain ring stage parasites $(30 \mathrm{~h})$, the late stage enriched iRBC were cultured overnight. The ring stage has previously been shown to be optimal for studies of var gene transcription [38] and is therefore used for RNA extraction. Total RNA was purified using Trizol (Invitrogen) and treated with DNAseI (Invitrogen) for $15 \mathrm{~min}$ at $37^{\circ} \mathrm{C}$. Superscript II was used to reverse transcribe DNAfree RNA primed with random hexamer primers (Invitrogen) at $25^{\circ} \mathrm{C}$ for $10 \mathrm{~min}, 42^{\circ} \mathrm{C}$ for $50 \mathrm{~min}$ followed by $70^{\circ} \mathrm{C}$ for 15 min. Quantitative real-time PCR was done using a Rotorgene thermal cycler system (Corbett Research, Motlake, Australia) and real-time PCR-optimized and gene-specific primers for each of the 59 fulllength var genes in the P. falciparum 3D7 genome [28,38]. Reactions were performed in $20 \mu \mathrm{l}$ volumes using QuantiTect SYBR Green PCR master mix (Qiagen, Merck Eurolab, Albertslund, Denmark) and $1 \mu \mathrm{M}$ primers. Quantification was done using Rotorgene software version 4.6. The housekeeping gene seryl-tRNA synthetase, which shows a uniform transcription profile in different parasite isolates and an unchanged pattern throughout the parasite life cycle, was used as an endogenous control as previously described [38] and used for calculations of percent measured transcript out of total var transcipts by the $\Delta \Delta \mathrm{CT}$ method (User Bulletin no. 2, Applied Biosystems).

\section{CD36 binding assay}

The CD36 binding assay was done as described in detail elsewhere [27]. To radiolabel parasites, cultures were incubated overnight in 10\% non-immune Danish plasma in RPMI 1640 in the presence of ${ }^{3} \mathrm{H}$-hypoxanthine. Monolayers of wild type, CD36- and CD54-transfected CHO cells and transformed human bone marrow endothelial cells (TrHBMEC) were grown in 96-well microtiter plates (Nunc, Roskilde, Denmark). Late stage enriched iRBC $\left(100 \mu \mathrm{l}, 1 \times 10^{7} \mathrm{iRBC} / \mathrm{ml}\right)$ were added to the $\mathrm{CHO}$ cell monolayer and incubated for 1 hour at $37^{\circ} \mathrm{C}$. After removal of unbound iRBC, the number of iRBCs adhering to the $\mathrm{CHO}$ cells was determined by liquid scintillation spectrometry.

\section{Results \\ Reduced expression of VAR4 following selection for CD36 binding}

To determine the effect of CD36 selection on VAR4 surface expression, mouse or rabbit antibodies against the CIDR1 $\alpha$ domain of VAR4 were used to stain three 3D7 sub-lines $-3 \mathrm{D} 7_{\mathrm{UM}}, 3 \mathrm{D} 7_{\mathrm{SM}-\mathrm{CD} 36}$ and $3 \mathrm{D} 7_{\mathrm{SM} \text {-drift }}$ and the parasite protein surface expression subsequently analysed by flow cytometry (Figure 1A). In agreement with what has been previously shown [28], 3D $7_{\mathrm{SM}}$ surface expressed VAR4, whereas $3 \mathrm{D} 7_{\mathrm{UM}}$ did not show any surface staining for VAR4 at the beginning of the experiment (Figure 1i-A). Similarly $3 \mathrm{D} 7_{\mathrm{SM}}$ showed high var4 transcription, whereas $3 \mathrm{D} 7_{\mathrm{UM}}$ only transcribed var4 at a very low level (Figure 1iB).

As a control, the VAR4 expressing $3 \mathrm{D} 7_{\mathrm{SM}}$ was left in culture for 44 generations from the day of the last antibody selection with gelatine flotation being carried out approximately every nine generations resulting in the $3 \mathrm{D} 7_{\mathrm{SM} \text {-drift }}$ sub-line. Both $3 \mathrm{D} 7_{\mathrm{SM}-\mathrm{CD} 36}$ and $3 \mathrm{D} 7_{\mathrm{SM} \text {-drift }}$ expressed VAR4 on the surface all throughout the experiment, but with the $3 \mathrm{D} 7_{\mathrm{SM}-\mathrm{CD} 36}$ sub-line showing a reduced level from the third panning (Figure 1ii-A and Figure 2). However, this reduction in VAR4 surface expression is not statistically significant $(\mathrm{p}=0.19$, Figure 2$)$. Following the fifth selection, VAR4 surface expression was borderline significantly lower in $3 \mathrm{D} 7_{\mathrm{SM}-\mathrm{CD} 36}$ compared with that in $3 \mathrm{D} 7_{\mathrm{SM}}(\mathrm{p}=$ 0.05 , Figure 2). Similarly, var4 gene transcription in the 3D7 sublines following the fifth selection was markedly lower in $3 \mathrm{D} 7_{\mathrm{SM}-\mathrm{CD} 36}(10 \%)$ as compared to the level of transcription in $3 \mathrm{D} 7_{\mathrm{SM}}(28 \%)$ (Figure 1iii-B). By contrast the transcription level of the group $\mathrm{B} / \mathrm{A}$ var gene PFF0010w (formerly known as MAL6P1.316)remained the same for both sub-lines ( $3 \mathrm{D} 7_{\text {SM-drift }}$ and $3 \mathrm{D} 7_{\text {SM-CD36 }}$ ) throughout the entire experiment (Figure 1ii-B and 1iiiB).

By using Western blotting for detection of VAR4 expression in $3 \mathrm{D} 7_{\text {SM-CD } 36}$ and $3 \mathrm{D} 7_{\text {SM-drift }}$ sub-lines, a distinct 400 kDa VAR4 band was expressed following all selections, but it was not possible to accurately quantify the amount of the protein due to the insufficient sensitivity of the technique. However, the transcriptional data and flow cytometry of live immuno-stained parasites indicate that the $3 \mathrm{D} 7_{\mathrm{SM}}$ parasites which bind to $\mathrm{CD} 36$ have reduced levels of VAR4 PfEMP1 surface expression (Figure 1i-iii and Figure 2).

\section{Increased adhesiveness to CD36}

To test whether the CD36 bio-panning increased the adhesiveness of $3 \mathrm{D} 7_{\mathrm{SM}}$ to the $\mathrm{CD} 36$ molecule, $3 \mathrm{D} 7_{\mathrm{UM}^{\prime}}$ $3 \mathrm{D} 7_{\mathrm{SM}-\mathrm{CD} 36}$ and $3 \mathrm{D} 7_{\mathrm{SM}-\text { drift }}$ binding assays were done using CD36 and CD54 (also known as intercellular adhesion molecule or ICAM-1) expressing $\mathrm{CHO}$ cell lines and $\mathrm{TrH}$ - 
i

3D7 UM
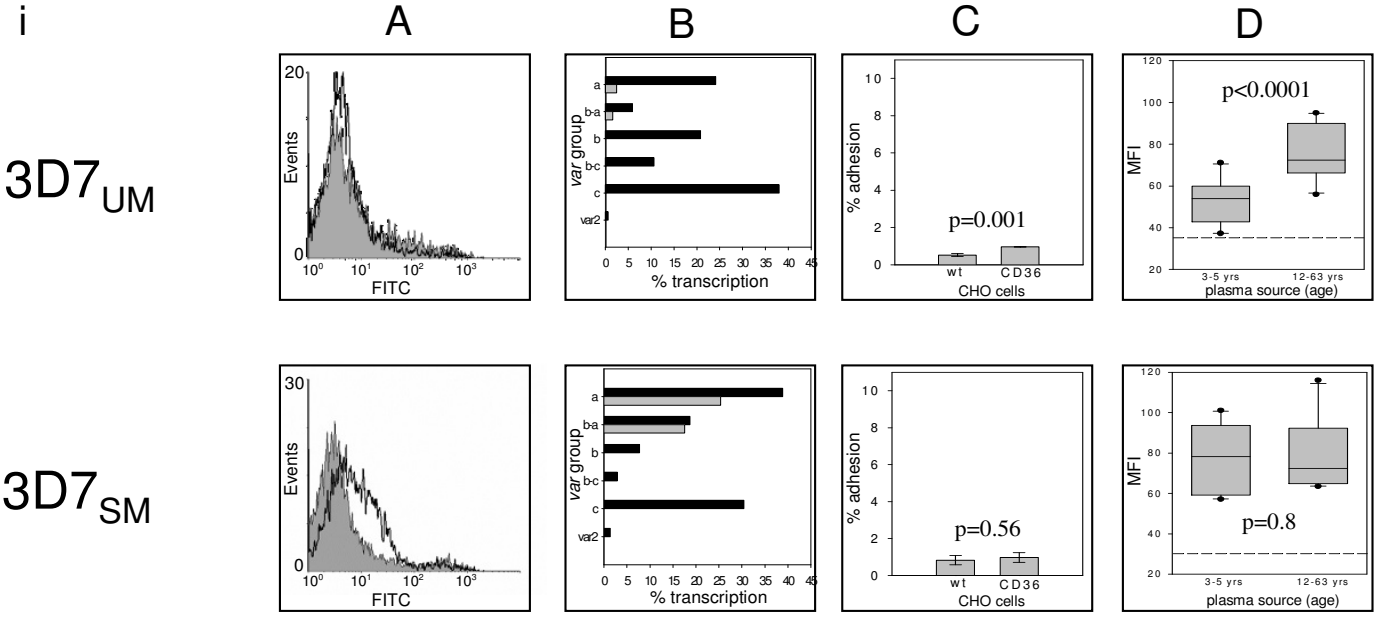

ii

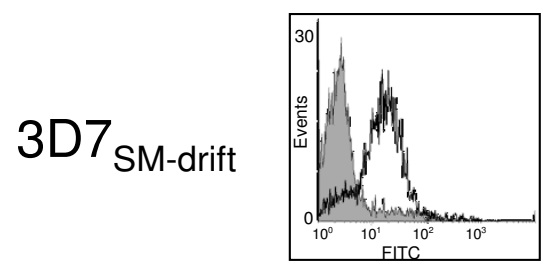

A

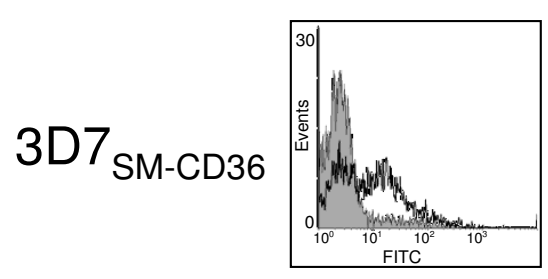

iii
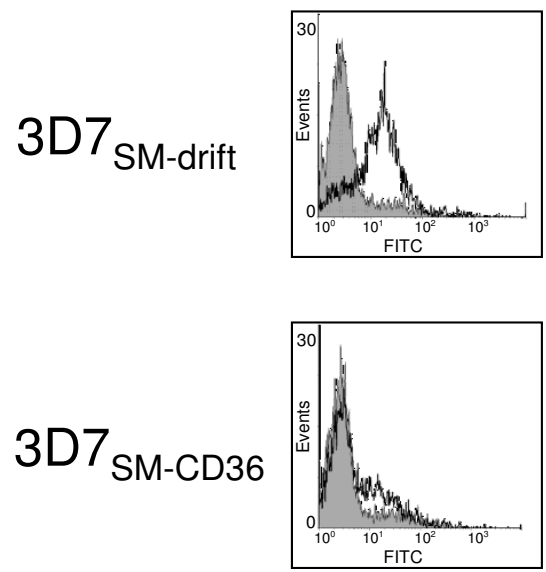
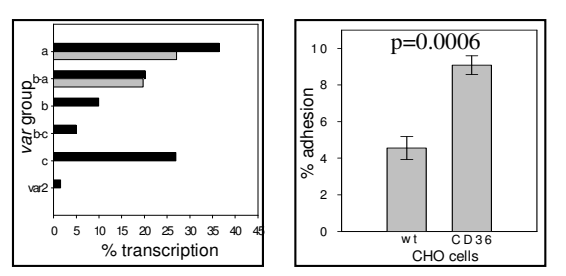

B
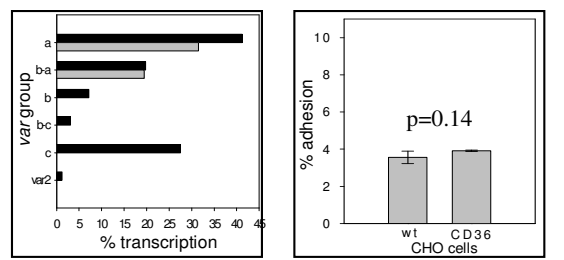

B
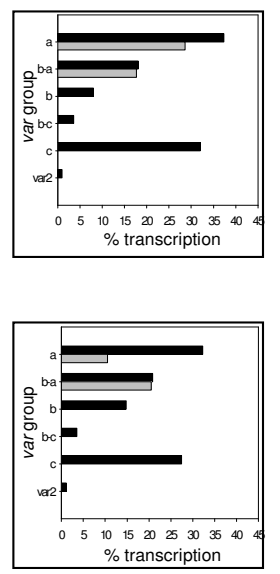

C
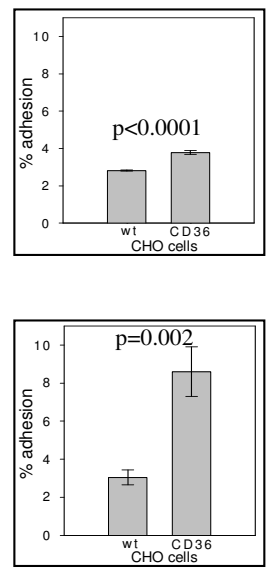
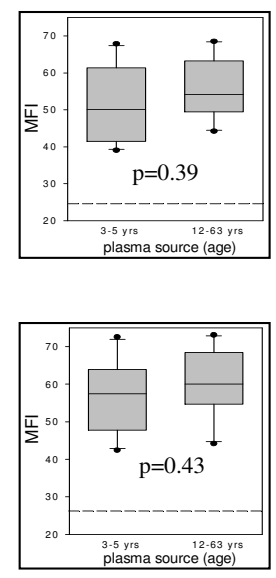

D

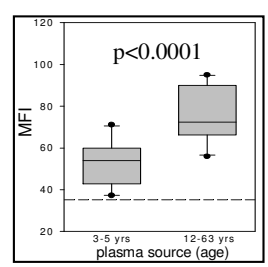

D

D
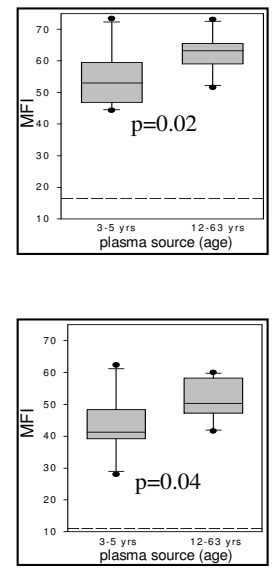

Figure I (see legend on next page) 
Figure I (see previous page)

Serological phenotypes, transcription and adhesion profiles of four $3 D 7$ sub-lines, $3 D 7_{S M}, 3 D 7_{U M}, 3 D 7_{S M-d r i f t}$ and 3D7 $7_{S M-C D 36}$. Panel (i): Parental 3D7 $7_{U M}$ and 3D7 $7_{S M}, 3 D 7_{S M}$ drift and 3D7 $7_{S M-C D 36}$ at the beginning of the experiment and following three (ii) and five (iii) rounds of gelatine flotation or selections for binding to CD36. Panel (A) shows the surface expression of VAR4 (open histograms) detected by flow cytometry using VAR4 anti-CIDR I $\alpha$ mouse (i) and rabbit anti-CIDR I $\alpha$ sera (ii and iii). Reactivity with pre-immunisation sera is shown for comparison (shaded histograms). Histograms are from one out of three replicate assays described in the Figure 2 legend. Panel $(B)$ shows the total percentage of ring-stage transcripts of each var gene group out of total var transcripts (black bars). Grey bars show the percentage transcription of var4 and PFF00 I Ow a group A and $B / A$ gene highly upregulated in the $3 D 7_{S M}$ compared to the $3 D 7_{U M}$ sub-line. Panel $C$ shows the percentage of iRBC adhering to wild type and CD36-transfected Chinese hamster ovary cells (CHO) compared with the total number of iRBC added to the plate. Bars are means of triplicate wells showing standard deviations and $p$ values. Panel $D$ shows t-tests comparing the recognition (average mean fluorescence intensities, MFI) of the different parasite sub-lines by plasma from 10 children (3-5 years) and 10 adults (12-63 years). The $95 \%$ confidence interval, standard deviations, outliers and $p$ values are shown. $p$ values $\leq 0.05$ were considered significantly different. The cut-off (reference line) was defined as the mean MFI values obtained using plasma from three Danish donors never exposed to malaria plus two times standard deviation.

BMEC. Due to high background adhesion of iRBC to wild type $\mathrm{CHO}$ cells only iRBC showing more than $8 \%$ binding to $\mathrm{CHO}-\mathrm{CD} 36$ as seen following the third and fifth panning (Fig 1ii-iiiC) of 3D7 ${ }_{\text {SM-CD36 }}$ were considered CD36 binders. Increased binding of 3 D $7_{\text {SM-CD36 }}$ to CD36 correlated well with reduced VAR4 expression and gene transcription (Figure 1A to $1 \mathrm{C}$ and Figure 2). The adhesion of $37_{\text {SM-drift }}$ to the CHO-CD36 was low in all selections (Figure $1 \mathrm{iC}-\mathrm{iiiC}$ ). Binding of $3 \mathrm{D}_{\mathrm{SM}-\mathrm{CD} 36}$ to $\mathrm{CHO}-\mathrm{CD} 54$ or TrHMBEC following bio-panning on CD36 did not differ from that of $3 \mathrm{D} 7_{\mathrm{SM} \text {-drift }}$ indicating that bio-panning on CD36 was specifically selecting for parasites binding to the CD36 receptor.

\section{Serological phenotypes of $3 D 7_{S M}$ selected for CD36 binding}

Consistent with previous published data $[27,28]$, unselected 3D7 predominantly expressed PfEMP1 $1_{\mathrm{UM}}$ and were better recognized by adults (12-63 years) than by children $(3-5$ years $)(p<0.0001)$ while $3 \mathrm{D} 7_{\mathrm{SM}}$ selected using IgG from semi-immune children was equally well recognized by plasma from both groups of individuals $(\mathrm{p}=0.8)$ (Figure 1i-D). Three to five rounds of gelatine flotation of $3 \mathrm{D} 7_{\mathrm{UM}}$ did not change the recognition pattern of this subline (data not shown). Following the third round of selection $3 \mathrm{D} 7_{\mathrm{SM}-\mathrm{drift}}$ and $3 \mathrm{D} 7_{\mathrm{SM}-\mathrm{CD} 36}$ had similar phenotypes to that of the original $3 \mathrm{D} 7_{\mathrm{SM}}$ (Figure $\left.1 \mathrm{i}-\mathrm{iiD}\right)$. Both sub-lines became significantly better recognized by adult plasma than by children's plasma after the fifth round ( 44 generations) of gelatine flotation $(\mathrm{p}=0.02)$ or CD36 selection ( $\mathrm{p}=0.04$, Figure 1iiiD) having serological profiles correlating slightly better with the baseline $3 \mathrm{D} 7{ }_{\mathrm{UM}}$ compared to the $3 \mathrm{D} 7_{\mathrm{SM}}$. Although borderline, this would indicate that both $3 \mathrm{D} 7_{\text {SM-drift }}$ and $3 \mathrm{D} 7_{\mathrm{SM}-\mathrm{CD} 36}$ have gradually shifted from expressing $\mathrm{PfEMP} 1_{\mathrm{SM}^{-}}$-type antigens to expressing PfEMP1 $1_{U M}$-type antigens.
Stability of VAR4 surface expression in ${ }^{3 D 7_{S M}}$ left to drift In the absence of CD36 selection VAR4 is stably expressed on the surface of $3 \mathrm{D} 7_{\mathrm{SM} \text {-drift }}$ for 44 generations - equivalent to five rounds of gelatine flotation (Figure 1iii-A). To analyse this further $3 \mathrm{D} 7 \mathrm{UM}$ and $3 \mathrm{D} 7_{\mathrm{SM}}$ were cultured without gelatine flotation or CD36 selection and monitored VAR4 surface expression and var4 transcription at specified time points for 94 generations. To avoid assay-toassay variation, RBC infected with the two parasite sublines were frozen down at each sampling point. Frozen iRBC were thawed and cultured for another six generations and then assayed on the same day. Almost no VAR4 surface expression and var4 gene transcription was seen in the parental $3 \mathrm{D} 7_{\mathrm{UM}^{\prime}}$, whereas $3 \mathrm{D} 7_{\mathrm{SM}}$-iRBC showed high and stable surface expression of VAR4 as well as gene transcription for at least 94 generations (Figure 3). Using the percentageVAR4 positive iRBC and the ring-stage var4 transcription level at generation six (first sampling point) and 94 (last sampling point) the switch off-rate was calculated to be less than $0.005 \%$ (Figure 3 ). Alternatively, with a switch off-rate that is virtually 0 , the minor differences observed at the transcription level may simply be due to experimental errors. Parallel to this, the two 3D7 sub-lines without prior freezing and thawing were assayed at every $\sim 9$ th generation and similarly found VAR4 expression and transcription to be stable for over six months in continuous in vitro culture.

\section{Discussion}

A previous study has shown that var4, a group A var gene, is highly transcribed and surface expressed in 3D7 parasites expressing $P f E M P 1_{S M}\left(3 D 7_{S M}\right)$ compared to $3 \mathrm{D} 7$ expressing PfEMP1 $1_{\mathrm{UM}}\left(3 \mathrm{D} 7_{\mathrm{UM}}\right)$, suggesting an association between VAR4 and severe malaria [28]. CD36 binding has in some studies been associated with disease severity. In a study in Kenya, a mutation in the CD36 gene among children has been associated with protection from severe malaria [39]. In addition, P. falciparum isolates from Thai 


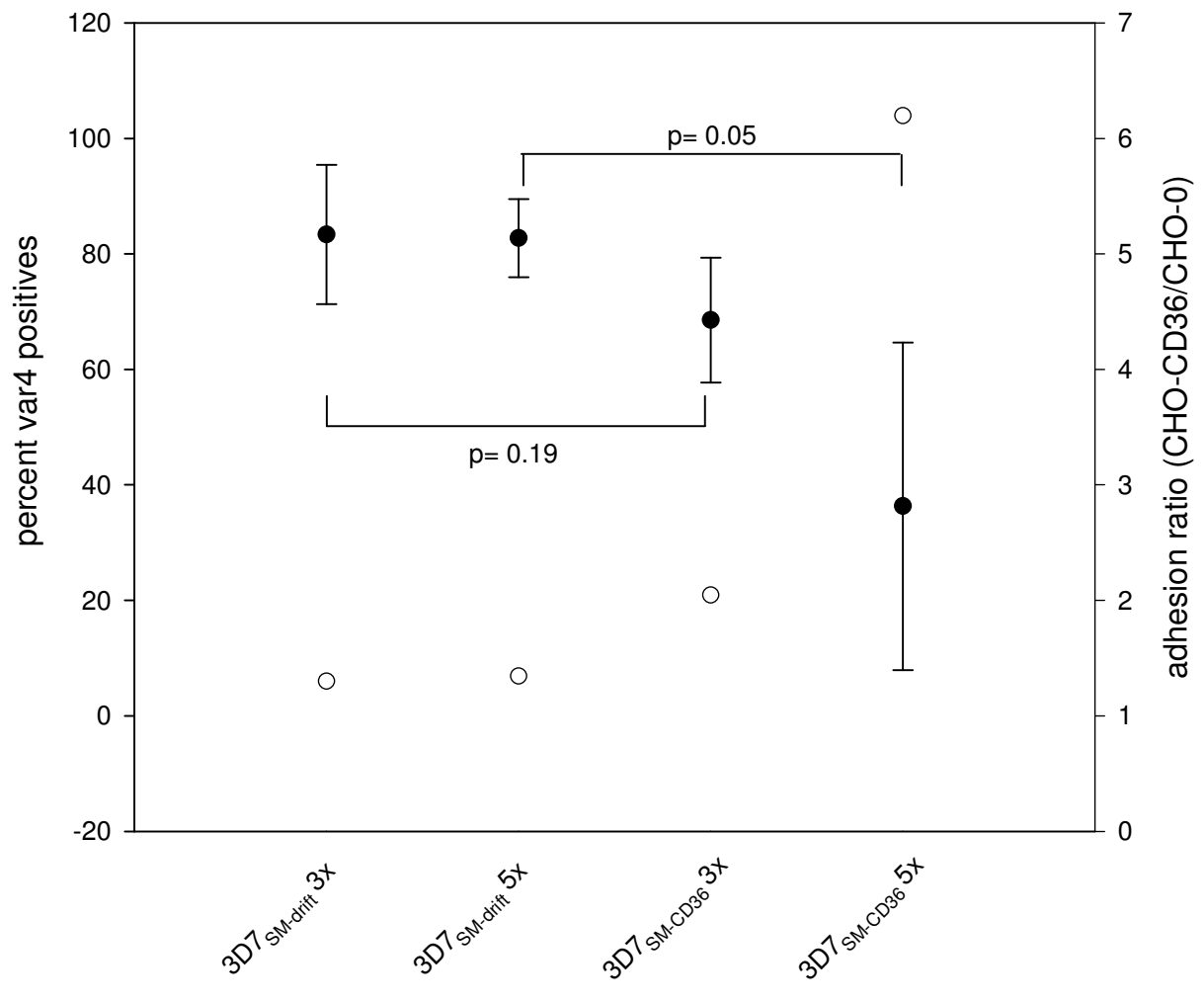

parasite line

\section{Figure 2}

VAR4 surface expression in $3 D 7_{S M-}$ drift and $3 D 7_{S M-C D 36}$ in 3 replicate experiments correlated with $C D 36$ adhesion. Left $Y$-axis, solid circles show mean percent VAR4 positives of $3 D 7_{S M-}$ drift and $3 D 7_{S M-C D 36}$ following three $(3 \times)$ and five $(5 \times)$ rounds of gelatine flotation or selections for binding to CD36 of three replicate experiments. Standard deviations are shown as error bars. The 3D7 sublines were not frozen nor thawed for the first replicate experiment prior to determination of VAR4 surface expression. For the second and third replicate experiments there was prior freezing, thawing, and in vitro culture of the 3D7 sublines. $\mathrm{P}$ values $\leq 0.05$ were considered significantly different. Right $\mathrm{Y}$-axis, open circles show adhesion ratio of the different 3D7 sublines. Adhesion ratio is calculated as percent adhesion to $\mathrm{CHO}-\mathrm{CD} 36$ over percent adhesion to $\mathrm{CHO}$ wild type.

adults suffering from severe but not cerebral malaria had higher CD36 adhesion than those from uncomplicated malaria patients [40]. In contrast, several studies are consistent with the notion that CD36 binding is not associated with particular virulent parasite phenotypes [27,28,30-32,41-43]. Robinson et al [31] has demonstrated in a heterologous expression assay that the CIDR1 region of VAR4 did not bind to CD36. There might be a conformational difference between the heterologous recombinant protein and the native protein presented on the iRBC or binding could be through a different domain. However, it remains that the current data on VAR4 expression on iRBC and CD36 binding phenotype support the prediction made by Robinson et al [31]. The current study has shown that VAR4 protein expression and var4 mRNA transcription are reduced following selection for CD36 binding, lending further support to the hypothesis that $\mathrm{PfEMP}_{\mathrm{SM}}$ antigens such as VAR4 are not involved in CD36 binding.

However, it is important to note that the correlation between severe malaria, the inability to bind to CD36 and group A var gene expression is not clear-cut $[4,31]$. ICAM1 binding may be associated with cerebral malaria as shown by previous studies [43-45]. But as demonstrated by Smith et al [4], at least two group B PfEMP1 that bind to ICAM-1 also bind to CD36. In addition, not all severe malaria isolates express group A var genes [42].

Selection of $3 \mathrm{D} 7_{\mathrm{SM}}$ for binding to CD36 lead to a reduced var4 gene transcription, but did not show any significant changes in other var genes as such. PFF0010w, a group B/ 


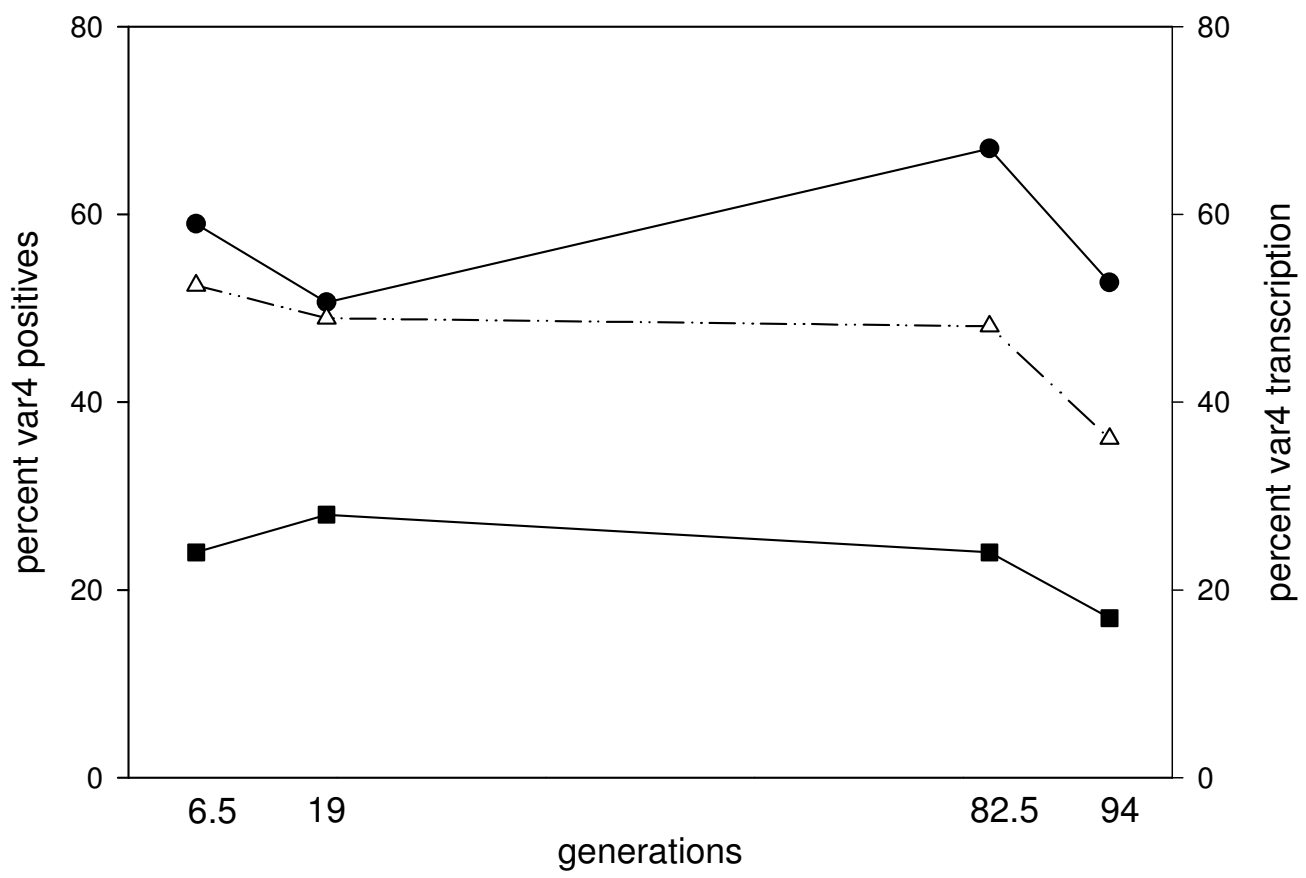

\section{Figure 3}

Changes in VAR4 surface expression and transcription of the $3 D 7_{S M}$ subline left to drift (3D7 SM-drift $_{\text {). Left }}$-axis, percentage of infected blood cells positive for VAR4 using flow cytometry and VAR4-specific CIDR I $\alpha$ (closed circle) and DBL5 $\delta$ (open triangle) rabbit antibodies. Right $Y$-axis, percentage var4 gene transcription in ring stage (closed square) parasites calculated as: (var4 absolute copy number/2copy number of all 3D7 var genes) $\times 100 \%$. Fluorescence of $3 \mathrm{D} 7_{\text {SM-drift }}$ Stained with pre-immune serum was used to separate positive cells from cells with background fluorescence.

A var gene upregulated in $3 \mathrm{D} 7_{\mathrm{SM}}$ together with var4 was previously predicted to be a non-CD36 binder based on its CIDR1 sequence [31]. In the current study however, selection on CD36 did not reduce PFF0010w transcription as would be expected. The reason for this is that PFF0010w is probably not expressed on the surface of $3 \mathrm{D} 7_{\mathrm{SM}}$ parasites as indicated by one distinct population of VAR4 expressing parasites in $3 \mathrm{D} 7_{\mathrm{SM}}$ and $3 \mathrm{D} 7_{\mathrm{SM} \text {-drift }}$ (Figure 1i-iiiA). Previous studies have shown that only one PfEMP1 is expressed on the surface at a time $[24,46]$ so these VAR4 expressing parasites are less likely to be expressing PFF0010w. However, a PFF0010w-specific antibody is needed to confirm this.

Although Group B and C var genes have been linked to CD36 binding [30,31], new protein bands were not detected in $3 \mathrm{D} 7_{\mathrm{SM}-\mathrm{CD} 36}$ using Western blots and anti-ATS antibodies compared to the protein band pattern seen in extracts of $3 \mathrm{D} 7_{\mathrm{SM}}$. Furthermore, the serological phenotype of $3 \mathrm{D} 7_{\mathrm{SM} \text {-drift }}$ and $3 \mathrm{D} 7_{\mathrm{SM}-\mathrm{CD} 36}{ }_{\mathrm{remaine}}$ similar when analysed by flow cytometry. These results might be explained by the fact that only $8 \%$ of the $3 \mathrm{D} 7_{\mathrm{SM}-\mathrm{CD} 36}$ parasites bound to the CD36 receptor while transcription and serological analysis was done on the entire parasite population. With the present set up it is difficult to determine the exact var genes involved in the CD36 adhesion of $3 \mathrm{D}_{\text {SM-CD36 }}$ although a slight increase in the total transcription level of group B var genes was noted in this sub-line at the end of the experiment (Figure 1iii-B). In order to determine the PfEMP1 involved in CD36 binding, both transcription and protein expression data are required.

Var gene transcription does not always reflect phenotypic expression as observed in this study, where VAR4 protein expression was poorly correlated with var4 transcription after the third CD36 panning (Figure 1ii-A and 1B). However, the fifth CD36 panning resulted to a higher correlation between var4 transcription and protein expression (Figure 1iii-A and 1B) most likely due to the more homogenous population as indicated by the dominant peak of VAR4 negative parasites in the histogram (Figure 1iiiA).

Studies have shown that var gene transcription peaks during the ring stage at 3-18-hour post invasion $[47,48]$ and that full length var transcript is not seen at all by Northern blotting at 24-34-hour post invasion [49]. In the current study, a 30-hour post invasion ring stage was used to measure var gene transcription. At 30 hours, the parasites 
appeared as non-pigmented thick ring forms under the microscope. An improved quantification of transcript abundances of each var gene obtained by quantitative real time PCR and the use of cross intron primers show that although the dominant full length transcript peaks at the ring stage, it remains dominant through out the life cycle [50].

In the absence of immune pressure var genes have been reported to have variable transition rates in vitro. There have been reports of transition rates as low as $0.025 \%$ [51] to as high as $2.4 \%$ [52] per generation. In the absence of CD36 selection and immune pressure, VAR4 surface expression is stable for more than six months in continuous in vitro culture with a transcription off rate of less than $0.005 \%$. For a PfEMP1 implicated in severe disease and expected to dominate in a host with limited immunity, it may not be surprising that VAR4 appears to have a low switching rate. Frank et al [53] have recently observed that, in the 3D7 isogenic line NF54, sub-telomeric var genes have higher off rates of approximately $1 \%$ compared with central var genes with 0 to $0.3 \%$ off rates. However, Frank et al [53] did not observe any activation of upsA genes in their experiments hence the high switch off rates of the sub-telomeric var genes reported were that of the ups $B$ promoter type. var4 is a sub-telomeric var gene with an upsA promoter suggesting the possibility that at least for some Group A var genes the switch rate might be comparable to that of central vars.

Both $37_{\text {SM-drift }}$ and $3 \mathrm{D} 7_{\text {SM-CD36 }}$ drifted away from a serological SM phenotype at prolonged in vitro culture to a more UM like phenotype. However, surprisingly the 3D7 ${ }_{\text {SM-drift }}$ remained positive for VAR4 surface expression raising the question whether VAR4 is the only PfEMP1 molecule contributing to the SM phenotype of the original antibody selected parasite, $3 \mathrm{D} 7_{\mathrm{SM}}$. To clarify this, in the current study, $3 \mathrm{D} 7_{\mathrm{UM}}$ was selected using VAR4 specific antibodies and found that only some and not all semiimmune plasma from children recognized $3 \mathrm{D} 7_{\mathrm{VAR} 4}$. This is an important finding because it points to the possibility that VSAs other than VAR4 might contribute to the serological phenotype of $3 \mathrm{D} 7_{\mathrm{SM}}$.

\section{Conclusion}

This study shows that increased CD36 adhesiveness of ${ }_{3 D} 7_{\text {SM-CD36 }}$ resulted in a reduction in VAR4 surface expression. In the absence of CD36 selection and immune pressure, VAR4 expression by $3 \mathrm{D}_{\mathrm{SM}}$ parasites is stable for at least six months while the population's serological phenotype drifts towards the UM phenotype. Results of this study shed more light on the characteristics of 3D7 parasites expressing VAR4 - a PfEMP1 previously associated with severe malaria phenotypes.

\section{Competing interests}

The authors declare that they have no competing interests.

\section{Authors' contributions}

PAM participated in the study design, carried out parasite work, flow cytometry experiments, data analysis and writing of the manuscript. TS participated in the study design, performed CD36 selection and binding assays, as well as serological phenotyping and data analysis. TGT helped in the study design and in finalizing the manuscript. LH helped in finalizing the manuscript. ATRJ participated in the study design, performed the RNA extractions, cDNA synthesis, all the Q-RT PCR experiments, analysed the data and helped drafting and writing the manuscript. All authors read and approved the final manuscript.

\section{Acknowledgements}

The study received financial support from the Danish International Development Assistance, The Danish Council for Health Science Research (grant no. 27I-05-0427) and the Commission of the European Communities (grant no. QLK2-CT-2002-0I 197, EUROMALVAC). PAM is supported by the Gates Malaria Partnership. ATRJ is supported by the Howard Hughes Medical Institute. Lotte Bram, Susanne Pedersen and Kirsten Pihl are thanked for excellent technical assistance. Visiting Niels Bohr professor David Arnot at University of Copenhagen is much appreciated for his suggestions and comments on the manuscript.

\section{References}

I. Baruch DI, Gormely JA, Ma C, Howard RJ, Pasloske BL: Plasmodium falciparum erythrocyte membrane protein $I$ is a parasitized erythrocyte receptor for adherence to CD36, thrombospondin, and intercellular adhesion molecule I. Proc Natl Acad Sci USA 1996, 93:3497-3502.

2. Chen Q, Barragan A, Fernandez V, Sundstrom A, Schlichtherle M, Sahlen A, Carlson J, Datta S, Wahlgren M: Identification of Plasmodium falciparum erythrocyte membrane protein I (PfEMPI) as the rosetting ligand of the malaria parasite $P$. falciparum. J Exp Med 1998, 187:15-23.

3. Chen Q, Heddini A, Barragan A, Fernandez V, Pearce SF, Wahlgren $M$ : The semiconserved head structure of Plasmodium falciparum erythrocyte membrane protein I mediates binding to multiple independent host receptors. J Exp Med 2000, 192:I-10.

4. Smith JD, Craig AG, Kriek N, Hudson-Taylor D, Kyes S, Fagen T, Pinches R, Baruch DI, Newbold Cl, Miller LH: Identification of a Plasmodium falciparum intercellular adhesion molecule-I binding domain: a parasite adhesion trait implicated in cerebral malaria. Proc Natl Acad Sci USA 2000, 97:1766-177I.

5. Reeder JC, Cowman AF, Davern KM, Beeson JG, Thompson JK, Rogerson SJ, Brown GV: The adhesion of Plasmodium falciparuminfected erythrocytes to chondroitin sulfate $A$ is mediated by P. falciparum erythrocyte membrane protein I. Proc Natl Acad Sci USA 1999, 96:5198-5202.

6. Baruch DI, Ma XC, Singh HB, Bi X, Pasloske BL, Howard RJ: Identification of a region of PfEMPI that mediates adherence of Plasmodium falciparum infected erythrocytes to CD36: conserved function with variant sequence. Blood 1997, 90:3766-3775.

7. Rowe JA, Moulds JM, Newbold Cl, Miller LH: $P$. falciparum rosetting mediated by a parasite-variant erythrocyte membrane protein and complement-receptor I. Nature 1997, 388:292-295.

8. Buffet PA, Gamain B, Scheidig C, Baruch D, Smith JD, HernandezRivas R, Pouvelle B, Oishi S, Fujii N, Fusai T, Parzy D, Miller LH, Gysin J, Scherf A: Plasmodium falciparum domain mediating adhesion to chondroitin sulfate A: a receptor for human placental infection. Proc Natl Acad Sci USA 1999, 96: I 2743-12748. 
9. Roberts DJ, Craig AG, Berendt AR, Pinches R, Nash G, Marsh K, Newbold Cl: Rapid switching to multiple antigenic and adhesive phenotypes in malaria. Nature 1992, 357:689-692.

I0. Biggs BA, Gooze L, Wycherley K, Wollish W, Southwell B, Leech JH, Brown GV: Antigenic variation in Plasmodium falciparum. Proc Natl Acad Sci USA I991, 88:9171-9174.

I I. Staalsoe T, Hamad AA, Hviid L, Elhassan IM, Arnot DE, Theander TG: In vivo switching between variant surface antigens in human Plasmodium falciparum infection. J Infect Dis 2002, 186:719-722.

12. Ofori MF, Dodoo D, Staalsoe T, Kurtzhals JA, Koram K, Theander TG, Akanmori BD, Hviid L: Malaria-induced acquisition of antibodies to Plasmodium falciparum variant surface antigens. Infect Immun 2002, 70:2982-2988.

13. Dodoo D, Staalsoe T, Giha H, Kurtzhals JA, Akanmori BD, Koram K, Dunyo S, Nkrumah FK, Hviid L, Theander TG: Antibodies to variant antigens on the surfaces of infected erythrocytes are associated with protection from malaria in Ghanaian children. Infect Immun 200I, 69:37|3-37I8.

14. Marsh K, Howard RJ: Antigens induced on erythrocytes by $\boldsymbol{P}$. falciparum: expression of diverse and conserved determinants. Science 1986, 231:150-153.

15. Marsh K, Otoo L, Hayes RJ, Carson DC, Greenwood BM: Antibodies to blood stage antigens of Plasmodium falciparum in rura Gambians and their relation to protection against infection. Trans R Soc Trop Med Hyg 1989, 83:293-303.

16. Bull PC, Lowe BS, Kortok M, Molyneux CS, Newbold Cl, Marsh K: Parasite antigens on the infected red cell surface are targets for naturally acquired immunity to malaria. Nat Med 1998, 4:358-360.

17. Baruch DI, Pasloske BL, Singh HB, Bi X, Ma XC, Feldman M, Taraschi TF, Howard RJ: Cloning the $P$. falciparum gene encoding PfEMP I, a malarial variant antigen and adherence receptor on the surface of parasitized human erythrocytes. Cell 1995, 82:77-87.

18. Smith JD, Chitnis CE, Craig AG, Roberts DJ, Hudson-Taylor DE, Peterson DS, Pinches R, Newbold Cl, Miller LH: Switches in expression of Plasmodium falciparum var genes correlate with changes in antigenic and cytoadherent phenotypes of infected erythrocytes. Cell 1995, 82:101-110.

19. Su XZ, Heatwole VM, Wertheimer SP, Guinet F, Herrfeldt JA, Peterson DS, Ravetch JA, Wellems TE: The large diverse gene family var encodes proteins involved in cytoadherence and antigenic variation of Plasmodium falciparum-infected erythrocytes. Cell I995, 82:89-100.

20. Taylor HM, Kyes SA, Harris D, Kriek N, Newbold Cl: A study of var gene transcription in vitro using universal var gene primers. Mol Biochem Parasitol 2000, I 05: I3-23.

21. Rubio JP, Thompson JK, Cowman AF: The var genes of Plasmodium falciparum are located in the subtelomeric region of most chromosomes. EMBO J 1996, I 5:4069-4077.

22. Fischer K, Horrocks P, Preuss M, Wiesner J, Wunsch S, Camargo AA, Lanzer M: Expression of var genes located within polymorphic subtelomeric domains of Plasmodium falciparum chromosomes. Mol Cell Biol I997, I 7:3679-3686.

23. Duffy MF, Brown GV, Basuki W, Krejany EO, Noviyanti R, Cowman $\mathrm{AF}$, Reeder JC: Transcription of multiple var genes by individual, trophozoite-stage Plasmodium falciparum cells expressing a chondroitin sulphate A binding phenotype. Mol Microbiol 2002, 43: I 285-1293.

24. Chen Q, Fernandez V, Sundstrom A, Schlichtherle M, Datta S, Hagblom $P$, Wahlgren $M$ : Developmental selection of var gene expression in Plasmodium falciparum. Nature 1998 , 394:392-395.

25. Noviyanti R, Brown GV, Wickham ME, Duffy MF, Cowman AF, Reeder JC: Multiple var gene transcripts are expressed in Plasmodium falciparum infected erythrocytes selected for adhesion. Mol Biochem Parasitol 200 I, I I 4:227-237.

26. Voss TS, Healer J, Marty AJ, Duffy MF, Thompson JK, Beeson JG, Reeder JC, Crabb BS, Cowman AF: A var gene promoter controls allelic exclusion of virulence genes in Plasmodium falciparum malaria. Nature 2006, 439:1004-1008.

27. Staalsoe T, Nielsen MA, Vestergaard LS, Jensen AT, Theander TG, Hviid L: In vitro selection of Plasmodium falciparum 3D7 for expression of variant surface antigens associated with severe malaria in African children. Parasite Immunol 2003, 25:42 I-427.
28. Jensen AT, Magistrado P, Sharp S, Joergensen L, Lavstsen T, Chiucchiuini A, Salanti A, Vestergaard LS, Lusingu JP, Hermsen R, Sauerwein R, Christensen J, Nielsen MA, Hviid L, Sutherland C, Staalsoe T, Theander TG: Plasmodium falciparum associated with severe childhood malaria preferentially expresses PfEMPI encoded by group A var genes. J Exp Med 2004, I 99: I I79- I I 90.

29. Kyriacou HM, Stone GN, Challis RJ, Raza A, Lyke KE, Thera MA Koné AK, Doumbo OK, Plowe CV, Rowe JA: Differential var gene transcription in Plasmodium falciparum isolates from patients with cerebral malaria compared to hyperparasitaemia. Mol Biochem Parasitol 2006, I 50:211-218.

30. Lavstsen T, Salanti A, Jensen AT, Arnot DE, Theander TG: Subgrouping of Plasmodium falciparum 3D7 var genes based on sequence analysis of coding and non-coding regions. Malar 2003, 2:27.

31. Robinson BA, Welch TL, Smith JD: Widespread functional specialization of Plasmodium falciparum erythrocyte membrane protein I family members to bind CD36 analysed across a parasite genome. Mol Microbiol 2003, 47: I 265-I278.

32. Bull PC, Pain A, Ndungu FM, Kinyanjui SM, Roberts DJ, Newbold Cl, Marsh K: Plasmodium falciparum antigenic variation: Relationships between in vivo selection, acquired antibody response, and disease severity. J Infects Dis 2005, I 92: I | | 19- I I 26.

33. Staalsoe T, Giha HA, Dodoo D, Theander TG, Hviid L: Detection of antibodies to variant antigens on Plasmodium falciparuminfected erythrocytes by flow cytometry. Cytometry 1999 , 35:329-336.

34. Jensen JB: Concentration from continuous culture of erythrocytes infected with trophozoites and schizonts of Plasmodium falciparum. Am J Trop Med Hyg 1978, 27:। 274-1276.

35. Nielsen MA, Staalsoe T, Kurtzhals JA, Goka BQ, Dodoo D, Alifrangis $M$, Theander TG, Akanmori BD, Hviid L: Plasmodium falciparum variant surface antigen expression varies between isolates causing severe and nonsevere malaria and is modified by acquired immunity. J Immunol 2002, I 68:3444-3450.

36. Askjaer N, Maxwell C, Chambo W, Staalsoe T, Nielsen MA, Hviid L, Curtis $C$, Theander TG: Insecticide-treated bed nets reduce plasma antibody levels and limit the repertoire of antibodies to Plasmodium falciparum variant surface antigens. Clin Diagn Lab Immunol 2001, 8: 1289-I29I.

37. Paul F, Roath S, Melville D, Warhurst DC, Osisanya JO: Separation of malaria-infected erythrocytes from whole blood: use of a selective high-gradient magnetic separation technique. Lancet I98I, 2:70-7|.

38. Salanti A, Staalsoe T, Lavstsen T, Jensen AT, Sowa MP, Arnot DE, Hviid L, Theander TG: Selective upregulation of a single distinctly structured var gene in chondroitin sulphate A-adhering Plasmodium falciparum involved in pregnancy-associated malaria. Mol Microbiol 2003, 49:|79-191.

39. Pain A, Urban BC, Kai O, Casals-Pascual C, Shafi J, Marsh K, Roberts $D$ : A non-sense mutation in Cd36 gene is associated with protection from severe malaria. Lancet 200I, 357:I 502-I503.

40. Ho M, Singh B, Looareesuwan S, Davis TM, Bunnag D, White NJ: Clinical correlates of in vitro Plasmodium falciparum cytoadherence. Infect Immun I991, 59:873-878.

4I. Aitman T], Cooper LD, Norsworthy PJ, Wahid FN, Gray JK, Curtis BR, McKeigue PM, Kwiatkowski D, Greenwood BM, Snow RW, Hill AV, Scott J: Malaria susceptibility and CD36 mutation. Nature 2000, 405:1015-1016.

42. Kirchgatter K, Portillo HA: Association of severe noncerebral Plasmodium falciparum malaria in Brazil with expressed PfEMPI DBLI alpha sequences lacking cysteine residues. Mol Med 2002, 8: 16-23.

43. Newbold C, Warn P, Black G, Berendt A, Craig A, Snow B, Msobo M, Peshu N, Marsh K: Receptor-specific adhesion and clinical disease in Plasmodium falciparum. Am J Trop Med Hyg 1997, 57:389-398.

44. Turner GD, Morrison H, Jones M, Davis TM, Looareesuwan S, Buley ID, Gatter KC, Newbold Cl, Pukritayakamee S, Nagachinta B, White NJ, Berendt AR: An immunohistochemical study of the pathology of fatal malaria. Evidence for widespread endothelial activation and a potential role for intercellular adhesion molecule-I in cerebral sequestration. Am J Pathol 1994, 145:1057-1069.

45. Fernandez-Reyes D, Craig AG, Kyes SA, Peshu N, Snow RW, Berendt AR, Marsh K, Newbold Cl: A high frequency African coding pol- 
ymorphism in the $\mathrm{N}$-terminal domain of ICAM-I predisposing to cerebral malaria in Kenya. Hum Mol Genet 1997, 6:1357-1360.

46. Scherf A, Hernandez-Rivas R, Buffet $P$, Bottius E, Benatar C, Pouvelle $B$, Gysin J, Lanzer M: Antigenic variation in malaria: in situ switching, relaxed and mutually exclusive transcription of var genes during intra-erythrocytic development in Plasmodium falciparum. EMBO J 1998, 17:5418-5428.

47. Kyes S, Pinches R, Newbold C: A simple RNA analysis method shows var and rif multigene family expression patterns in Plasmodium falciparum. Mol Biochem Parasitol 2000, 105:3 II-3 I5.

48. Ralph SA, Bischoff E, Mattei D, Sismeiro O, Dillies M-A, Guigon G, Coppee J-Y, David PH, Scherf A: Transcriptome analysis of antigenic variation in Plasmodium falciparum - var silencing is not dependent on antisense RNA. Genome Biology 2005, 6:R93.

49. Voss TS, Kaestli M, Vogel D, Bopp S, Beck HP: Identification of nuclear proteins that interact differentially with Plasmodium falciparum var gene promoters. Mol Microbiol 2003, 48:1593-1607.

50. Dahlbäck M, Lavstsen T, Salanti A, Hviid L, Arnot DE, Theander TG, Nielsen MA: Changes in var gene mRNA levels during erythrocytic development in two phenotypically distinct Plasmodium falciparum parasites. Malaria / 2007, 6:78.

5I. Horrocks P, Pinches R, Christodoulou Z, Kyes SA, Newbold CI: Variable var transition rates underlie antigenic variation in malaria. Proc Natl Acad Sci USA 2004, I 0 I: I I I 29- I I I 34.

52. Roberts DJ, Craig AG, Berendt AR, Pinches R, Nash G, Marsh K, Newbold Cl: Rapid switching to multiple antigenic and adhesive phenotypes in malaria. Nature 1992, 357:689-692.

53. Frank M, Dzikowski R, Amulic B, Deitsch K: Variable switching rates of malaria virulence genes are associated with chromosomal position. Mol Microbiol 2007, 64: 1486-1498.

Publish with Biomed Central and every scientist can read your work free of charge

"BioMed Central will be the most significant development for disseminating the results of biomedical research in our lifetime. "

Sir Paul Nurse, Cancer Research UK

Your research papers will be:

- available free of charge to the entire biomedical community

- peer reviewed and published immediately upon acceptance

- cited in PubMed and archived on PubMed Central

- yours - you keep the copyright

Submit your manuscript here:

http://www.biomedcentral.com/info/publishing_adv.asp
BioMedcentral 